\title{
Alkylidenephosphines and Diphosphetanes
}

G. BECKER * B. BECKER, W. BECKER, AND W. UHL

Institut für Anorganische Chemie der Universităt stuttgart

Pfaffenwaldring 55

D-7000 stuttgart 80

In studies of the reactivity and thermal stability of various alkylidenephosphines prepared from benzophenone and organylbis(trimethylsilyl)phosphines via a NaOH-catalyzed elimination of hexamethyldisiloxane (eq. 1a), detailed analy${ }_{\mathrm{R}}^{\mathrm{R}} \mathrm{C}=\mathrm{E}+$<smiles>[R]P([Y])[AsH2]</smiles><smiles>[Y][AsH2]CC</smiles><smiles>[R]P=C([R])[R]</smiles>
(eq. 1)

eq. $1 \mathrm{a}: \mathrm{R}^{1}=\mathrm{H}_{5} \mathrm{C}_{6} ; \mathrm{E}=\mathrm{O} ; \mathrm{x}=\left(\mathrm{H}_{3} \mathrm{C}\right)_{3} \mathrm{Si}$

eq. 1b: $\mathrm{R}^{1}=\left(\mathrm{H}_{3} \mathrm{C}\right)_{3} \mathrm{C} ; \mathrm{E}=\mathrm{S} ; \mathrm{X}=\mathrm{Li} \cdot 2 \mathrm{THF}$

ses of $\mathrm{nmr}$-spectra and $\mathrm{x}$-ray structure determinations prove the methyl derivative $\underline{1 a}$ to dimerize to an 1,3-diphosphetane (2a), whereas from the iso-propyl compound $1 \mathrm{~b}$ the 1,2-diphosphetane 2b is obtained [1]. This observation confirms our hypothesis that the formation of 1,2- or 1,3-diphosphetanes is determined by the steric requirements of the substituent at phosphorus.

Alkylidenephosphines with two bulky substituents at the carbon atom of the $\mathrm{P}=\mathrm{C}$ moiety as e.g. two tert-butyl groups remain monomeric. These compounds are readily prepared from di(tert-butyl)thioketone and a lithium organyltrimethylsilylphosphide (eq. 1b). With lithium bis(trimethylsilyl)phosphide a mixture of [di(tert-butyl)methylidene]trimethylsilylphosphine (3), tris(trimethylsilyl) phosphine, and the structurally characterized 2,3-diphospha-1,3-butadiene $\underline{4}$ is obtained.<smiles>C[AsH2]P=C(C(C)(C)C)C(C)(C)C</smiles>

Treatment of compound 3 with methanol yields di(tert-butyl)methylidenephosphine 5 which dimerizes via a $P-H$ addition of one molecule to the $P=C$ group of a second one.

[1] G. Becker, B. Becker, W. Becker: Z. anorg. allg. Chem., in press. 